XII. Notes on the Ontogeny and Morphology of the male genital tube in Coleoptera. By Frederick Muir, F.E.S.

[Read June 5th, 1918.]

\title{
Plate X.
}

In a former paper* I described some stages in the development of the male genitalia of some species of Coleoptera. Since then I have filled in a few more stages of the same species, but I have not been able to extend my observations to other forms. I would not consider it of any use to repeat what I have said elsewhere were it not that some of the leading authorities on insect morphology have failed to understand the structure of the organ, and most workers repeat their statements without any qualifications. Kolbe + in describing the male genitalia of Rhynchophorus phoenicis has mistaken the eighth abdominal segment for the aedeagus, and the rectum for the ejaculatory duct. Several writers have stated that the median lobe and the tegmen are composed of amalgamated paired lobes or parameres, and others have stated that certain segments, or parts of segments, of the abdomen are included in the structure. As an extreme exponent of this latter view I may quote Hopkins, + who has tried to homologise the armature on the internal sac with parts of the tenth abdominal segment. I can find no evidence to support these views either in development or comparative morphology.

\section{Development.}

In the early stages of Rhabdocnemis obscura (Boisd.) the testes are connected by a $\mathbf{Y}$-shape thread to a median point between the ninth and tenth abdominal sternites. During the development of the pupa the area where the thread is attached to the body wall invaginates and forms the genital invagination. The bottom of this invagination

* Psyche 22 (1915), pp. 147-152, pl. XII.

† "Einführung in die Kenntnis der Insekten," 1893, p. 322, figs. $225,226,227$.

‡ "On the genus Pissodes," U. S. Dep. Agric. Ent. Tech. Ser. 20, I, 1911 .

TRANS. ENT. SOC. LOND. 1918.-PARTS I, II. (DEC.) 
grows out or evaginates, and eventually forms the eurazygos, the stenazygos being formed by an invagination at the apex of the eurazygos. The first differentiation of the eurazygos is a constriction near the base, differentiating the tegmen from the median lobe. This I call the tegminal fold, and it is of great morphological importance; from it are developed the tegminal lobes as two evaginations, ard the tegminal strut as a single invagination. In $R$. obscura (Boisd.) there are no tegminal lobes, but there is a large strut, the origin of which as an invagination eventually becoming thickly chitinised is quite plain. The portion of the eurazygos distad of the tegminal fold develops into the median lobe and the internal sac; at first there is no differentiation between these two, but at a later stage the basal portion becomes chitinised and differentiated as the median lobe, while the distal portion remains membranous and as it increases in size it crumples up and ultimately it is withdrawn into the median lobe, but not until the beetle is fully developed and has left the pupal skin. In $R$. obscura (Boisd.) there is a pseudo-tegmen formed by the chitinisation of the connecting membrane between the tegmen and the wall of the abdomen, and in this species the spiculum gastrale arises as an invagination from the pseudo-tegmen.

The male genitalia of Coccinella repanda arise in a similar manner from the same position between the ninth and tenth sternites. Soon after the tegminal fold is developed two broad, flat processes grow out from it, and a small invagination takes place on the opposite aspect of the fold; the former are the tegminal lobes and the latter is the tegminal strut. The tegminal fold beneath (or at the base of) the tegminal lobes grows outward carrying the tegminal lobes with it, and eventually forms the median "cap-piece." The median lobe elongates and muscles connect its base with the tegminal strut, and as it lengthens and grows inward it becomes curved. The spiculum is formed by an invagination near the base of the ninth sternite.

Carpophitus humeralis also follows a similar line of development, the tegminal lobes first appearing as broad, rounded outgrowths of the tegminal fold, the tegminal strut being very small. The apical portion of the eurazygos is invaginated at an early stage and grows inward to a great length, an evagination takes place at the junction of the eurazygos and stenazygos which lengthens into the fine, 
long flagellum. At a later stage the median lobe is differentiated, but the basal portion of the internal sac is not withdrawn into the short median lobe until the insect is mature. The median strut arises as an invagination at the base of the median lobe. At first both the median and tegminal struts are simple, tubular invaginations, but at a later stage the former becomes dilated at the apex, and the latter broad and thin.

\section{Comparative Morphology.}

If we examine the abdomen of a generalised trilobe coleopteron nine or even ten tergites and nine sternites can be easily discerned (in Enarsus bakewelli there is a distinct tenth sternite lying between the anus and the aedeagus). In the Dermestid figured * there are nine complete abdominal segments, the anus opening on a small membranous tube below the ninth tergite, the aedeagus lying between the anus and the ninth sternite. The ninth segment forms a complete ring, and is prolonged into the abdomen as a strut on the ventral aspect. In Rhynchophorus ferrugineus only eight abdominal segments can be traced; the eighth tergite is large, boatshaped, deeply cleft at the base and slightly so at the apex, with the eighth spiracle on the pleural area; the eighth sternite is small and lies across the ventral aspect of the eighth tergite, and together they form a tube through which the aedeagus plays; the anus lies beneath the eighth tergite, between the eighth tergite and the aedeagus. The cloaca so formed is closed by the meeting of the posterior edges of the seventh tergite and seventh sternite. In Rhabdocnemis obscura (Boisd.) a similar condition prevails. In both these forms the connecting membrane is chitinised and forms a pseudotegmen; in Rhynchophorus there is no spiculum. In Acantholophus and Ithycerus the cloaca is closed by the meeting together of the posterior edges of the eighth tergite and seventh sternite, the eighth sternite is small and, together with the eighth tergite, forms a tube through which the aedeagus plays. In the former there is a large spiculum arising some distance from the base of the connecting membrane, in the latter there is a distinct spiculum and also a strut from the basal edge of the eighth sternite; the

* This is a common species in Honolulu, but I have no name for it at present, and no specimens in England.

TRANS. ENT. SOC. LOND. 1918,-PARTS I, II. (DEC.) Q 
eighth spiracle is plainly discernible in both these genera. In Hylesinus crenatus there is no chitinised eighth sternite, and the spiculum is highly developed and serves in the place of the sternite as part of the tube through which the aedeagus plays. In some allied forms the eighth sternite is represented in various states of dechitinisation (or degeneration). The anal opening in these forms is situated on the membrane between the eighth tergite and the aedeagus (on the dorso-basal portion of the connecting membrane).

\section{Conclusions.}

The evidence derived from observations on the development of the male genital tube in Coleoptera indicates that it is a tubular organ arising in a median position from the connecting membrane between the ninth and tenth sternites. There is no evidence whatever to indicate that it is composed of amalgamated paired organs (called parameres by some authors). The tegminal lobes, cap-piece and tegminal strut are secondary outgrowths from the tegminal fold.

The comparative study of the morphology does not indicate that any abdominal segment or sternite is incorporated into the tube. In certain forms we find that ten tergites and ten sternites are actually present, or ten tergites and nine sternites, and the aedeagus consists of complete tegmen with tegminal lobes and basal piece and complete median lobe; in other forms some of the segments or parts of segments are dechitinised and withdrawn into the cloaca, but the aedeagus in these forms only contains the same parts as do those forms in which the segments are chitinised and therefore demonstrable. It is therefore illogical to consider the missing segments as incorporated into the genital tube. In fact the evidence points the other way, as in those forms in which the abdominal segments are reduced there is generally a great reduction in the tegmen. As the spiculum is an invaginated secondary tube which becomes highly chitinised it is difficult to understand how it can represent a sternite, and the most we can say is that it arises from, or near to the position of the ninth sternite, in the same manner as the false spiculum, or strut, in Ithycerus and Belus arises from the edge of the eighth sternite. Apodemes similar to the spiculum in origin (invaginations of the ectoderm) arise in various parts of the body in insects and do not represent a sternite or a tergite, and occur in positions 
where the surface of the body wall does not allow a large enough surface for the attachment of muscles. In Rhabdocnemis obscura (Boisd.) the spiculum arises from the side of the pseudo-tegmen some distance from the opening of the cloaca, and, as already stated, in Rhynchophorus there is no spiculum. In Platypus also the spiculum is absent. It is probable that the spicula in different groups are not homologous.

The theory of the origin of the genital tube by the amalgamation of paired organs finds its chief support in the analogy drawn from such forms as the Dermaptera. In that order there is a $\mathbf{Y}$-shaped organ consisting of a single basal piece with a pair of parameres. In one group (Protodermaptera) there are two penes, one arising from each paramere; in another group (Eudermaptera) there is only a single median penis. This latter form is similar in construction to the trilobe form of Coleoptera. I can find no evidence to show that the single basal portion of the organ is formed by the amalgamation of two parameres, and it is quite possible, and even probable, that the parameres are secondary developments, the same as the tegminal lobes in Coleoptera. The formation of the single median penis of the Eudermaptera is not by the amalgamation of the two, but by the suppression of one penis and the increased growth of the other. Thus the analogy from Dermaptera gives no support to the theory of the paired origin of the tegmen, and refutes the theory of such an origin of the median lobe.

It may be thought (though there is no evidence to indicate it, and it is very improbable) that Coleoptera had paired genital openings, or that Protocoleoptera possessed them. The time when the ancestors of the order could have been in that condition is so remote that it can have no bearing upon the question. It is probable that the immediate preceding stage to the Coleoptera or Protocoleoptera was such as is found to-day in Zoraptera Silvestri, where there is a single duct opening in a median position, a portion of which is most probably protruded during copulation. It is the telescoping and chitinisation of this eversible portion of the duct that has constituted the organ as we now know it.

In the Anoplura and Mallophaga we have an arrangement of parts in the male genitalia similar to those in the trilobe forms of Coleoptera, with similar lines of development in both groups. That these are cases of parallel development 
and have no phylogenetic significance no entomologist of any standing will deny.

Whilst recognising the great interest and value of much of the work in comparative morphology of "recent years, I cannot help entering a protest against the methods of some of the workers who have made a fetish of homology. Having selected what they consider to be a generalised form they proceed to delineate and name each sclerite, and then set themselves to discover similar sclerites in other more specialised types. It is under the influence of this idea that certain workers profess to find portions of the tenth tergite and sternite in the armature and chitinisations on the internal sac. If they would remember that an insect is a double membranous tube with a number of invaginations and evaginations, certain areas of which become more or less stiffened by the deposition of chitin, and that the male genitalia of Coleoptera is a tubular evagination arising from a median position between the ninth and tenth abdominal sternites, they might recognise the improbability, or even the impossibility, of a tergite or portion of a tergite becoming attached to the apex of a tubular organ in such a situation.

My thanks are due to Dr. David Sharp for much interesting information, and for placing at my disposal his large collection of dissections made since we published our joint paper on this subject in 1912 .

\section{Explanation of Plate X.}

\section{Figures.}

No. 1. Rhabdocnemis obscura (Boisd.).--Early stage of male genitalia in the pupa. $\mathrm{Cm}$, wall of the genital invagination; $t f$, tegminal fold; $m l+i s$, median lobe and internal sac; fo, the functional orifice will eventually open here; $e j$, ejaculatory duct; $m$, embryonic muscles between the eurazygos and the stenazygos.

No. 2. The same about half developed.

No. 3. The same fully developed or nearly so.

No. 4. Coccinella repanda. - Early stage of male genitalia in the pupa.

No. 5. The same three-fourths developed.

No. 6. Carpophilus humeralis.-Early stage of male genitalia in the pupa.

No. 7. The same nearly fully developed.

o. 8. Dermestis, sp., showing the nine abdominal segments and $\mathrm{N}$ the aedeagus. 
Trans. Ent. Soc. Lond., I9I8, Plate X.
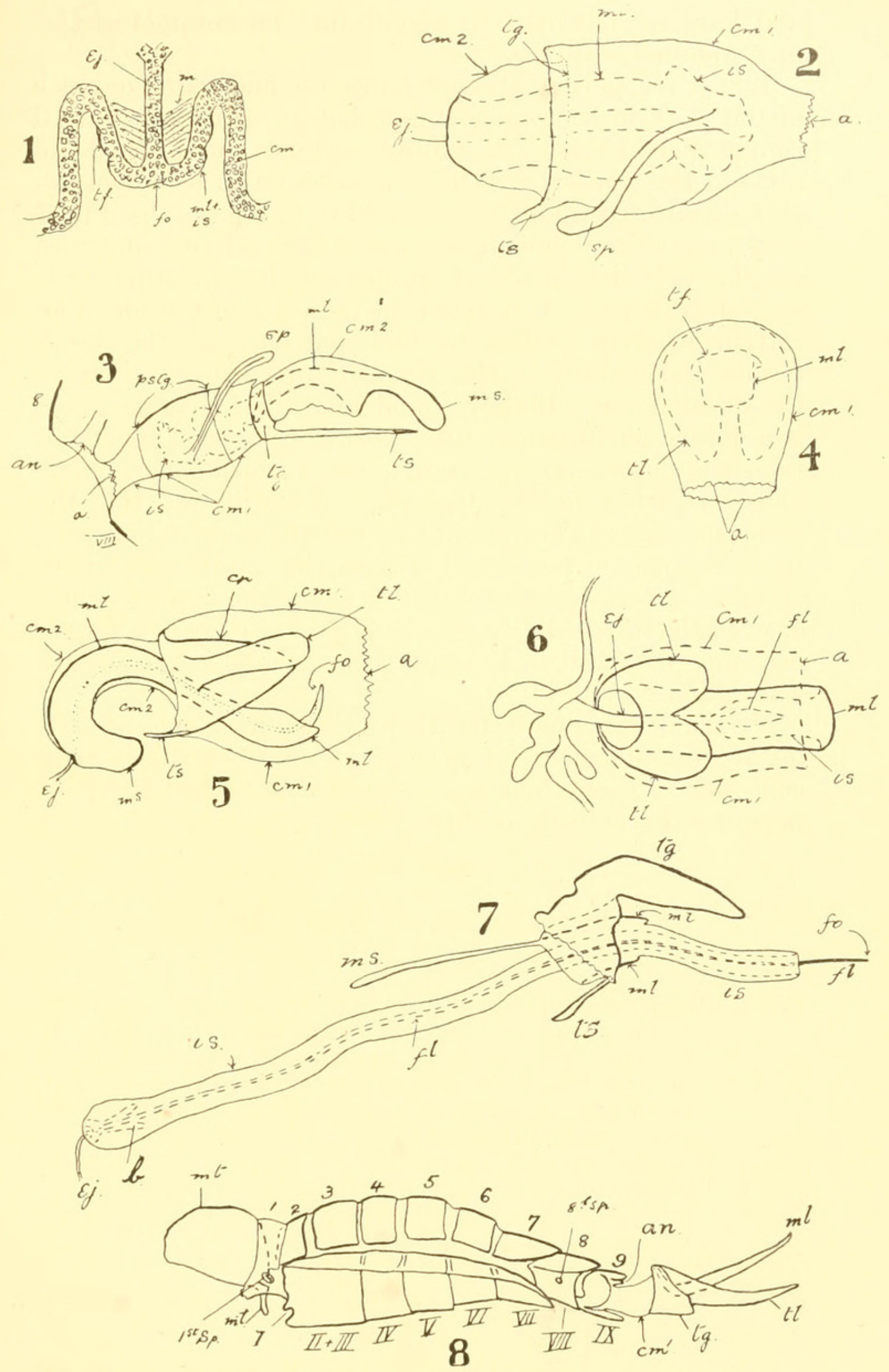

DEVELOPMENT OF MALE GENitAlia. COLEOPTERA. 



\section{$2 \mathrm{BHL}$ Biodiversity Heritage Library}

Muir, F. 1918. "Notes on the Ontogeny and Morphology of the male genital tube in Coleoptera." Transactions of the Entomological Society of London 66, 223-230. https://doi.org/10.1111/j.1365-2311.1918.tb02596.x.

View This Item Online: https://www.biodiversitylibrary.org/item/51007

DOI: https://doi.org/10.1111/j.1365-2311.1918.tb02596.x

Permalink: https://www.biodiversitylibrary.org/partpdf/18516

\section{Holding Institution}

Smithsonian Libraries

\section{Sponsored by}

Smithsonian

\section{Copyright \& Reuse}

Copyright Status: Public domain. The BHL considers that this work is no longer under copyright protection.

This document was created from content at the Biodiversity Heritage Library, the world's largest open access digital library for biodiversity literature and archives. Visit BHL at https://www.biodiversitylibrary.org. 